\title{
SPECTRUM OF FINDINGS IN PATIENTS PRESENTING FOR UPPER GASTROINTESTINAL ENDOSCOPY AT A TERTIARY CARE HOSPITAL AND THE INFLUENCE OF AGE AND GENDER
}

\author{
Fayyaz Hassan, Khalil Ahmad, Saeed Bin Ayaz*, Heyyan Bin Khalil** \\ Combined Military Hospital Kharian/National University of Medical Sciences (NUMS) Pakistan, *Combined Military Hospital Jhelum/National University of \\ Medical Sciences (NUMS) Pakistan, **The University of Oklahoma, Oklahoma, United State of America
}

\begin{abstract}
Objective: To determine the spectrum of findings in patients presenting for upper gastrointestinal (UGI) endoscopy and investigate role of age and gender.

Study Design: Cross-sectional study.

Place and Duration of Study: Department of Gastroenterology \& Internal Medicine, Combined Military Hospital Kharian, from Jul 2017 to Mar 2019.

Methodology: The data regarding 638 consecutive patients who underwent upper gastrointestinal endoscopy in the department were collected from the computer-based database and patients were stratified into two groups according to their age: $\leq 50$ and $>50$ years.

Results: The mean age was $50.2 \pm 17.4$ (range: 7-100) years. There were 431 males and 207 females. The commonest presenting complaint was decompensated chronic liver disease (CLD) 162 (25.4\%). The upper gastrointestinal endoscopy was normal in $306(48 \%)$ and abnormal in $332(52 \%)$ patients. The commonest abnormality seen on upper gastrointestinal endoscopy was esophageal varices seen in 167 (26.2\%) followed by non-specific gastropathy, and hiatal hernia seen in 28 (4.4\%) and 21 (3.3\%) patients respectively. No significant differences were observed among males and females for a positive upper gastrointestinal endoscopy. Significantly large number of patients of age $>50$ years had an abnormal upper gastrointestinal endoscopy ( $p$ $<0.001$ ). The commonest upper gastrointestinal endoscopic abnormalities were similar in both genders and age-groups.

Conclusion: The commonest finding on upper gastrointestinal endoscopy were esophageal varices and non-specific gastropathies. Females and patients $\leq 50$ years had a higher prevalence of a normal upper gastrointestinal endoscopy. The commonly observed upper gastrointestinal endoscopy findings were generally similar among the genders and the age-groups.
\end{abstract}

Keywords: Decompensated chronic liver disease, Gastropathy, Hiatal hernia, Upper gastrointestinal endoscopy, Varices.

This is an Open Access article distributed under the terms of the Creative Commons Attribution License (https://creativecommons.org/licenses/by-nc/4.0/), which permits unrestricted use, distribution, and reproduction in any medium, provided the original work is properly cited.

\section{INTRODUCTION}

Upper gastrointestinal (UGI) problems are reasonably prevalent in the general population at large. Dyspepsia is a general term used to describe a constellation of symptoms related to the UGI tract. It includes epigastric burning or pain, upper abdominal fullness after taking meals, and early satiation as elaborated by the joint statement given by an international committee of clinical investigations ${ }^{1}$. Worldwide, $15-20 \%$ people in many developed countries complain of dyspepsia at regular or intermittent basis 2,3 .

Dyspepsia is mostly considered a benign disease (functional belching, post prandial discomfort, etc.) but sometimes, it is an earlier manifestation of a graver disease e.g. peptic ulceration, cholelithiasis, gastric carcinoma, etc., where it is termed as organic dyspepsia. The initial cost-effective approach towards a person with dyspepsia is to test for antibodies against Helicobacter pylori and treat the infection if the test is

Correspondence: Dr Fayyaz Hassan, Classified Medical Specialist \& Gastroenterologist, CMH Kharian Pakistan

Received: 29 May 2019; revised received: 09 Aug 2019; accepted: 16 Aug 2019 positive $^{4}$. If the antibodies are absent, an empiric therapy with a proton pump inhibitor or an $\mathrm{H} 2$ receptor antagonistwith or without a prokinetic agent is recommended 4 . If symptoms persist or recur after six to eight weeks of empiric therapy, UGI endoscopy should be performed 4 . UGI endoscopy is also the initial investigation of choice if a person has alarming features such as dysphagia, hematemesis, and/or melena 4 .

UGI endoscopy has evolved considerably since its inception in $1960^{5}$. Its use is getting more common for the treatment of gastro luminal pathologies. UGI endoscopy is aimed at recognition of the particular etiology so that the precise therapy can be started. Early endoscopy for every patient with UGI symptoms may come up with normal results and may not be cost-effective but it reassures the patient and his/her physician to gether $4,6,7$. The aim of this study was to identify the spectrum of diseases found on UGI endoscopy in patients presenting with different gastrointestinal symptoms at Kharian city and compare the male and female genders and the age groups to explore any association with any of the disease. 


\section{METHODOLOGY}

This retrospective study was carried out at the department of Gastroenterology \& Internal Medicine, Combined Military Hospital (CMH) Kharian while considering data of patients from July 2017 to March 2019. The approval from the hospital ethics committee was obtained before starting the study. Other ethical issues were settled according to the directions of the declaration of Helsinki. A sample size of 133 was estimated via Epi Tools Epidemiological calculator 8 while keeping level of significance 5\%, confidence level 95\%, estimated true proportion $35 \%, 9$ and $5 \%$ of absolute precision. All individuals who underwent UGI endoscopy in the department were sampled through consecutive sampling. CMH Kharian is a tertiary care hospital in Gujrat district of the Punjab province. The hospital provides medial services to an areaof nearly ten million people. The UGI endoscopy unit started functioning in 2002. It receives patients from the in-door and out door departments of the same hospital and other outpatient clinics and hospitals in the vicinity. Patients generally are from variable socioeconomic backgrounds.

The criteria for inclusion in the study were patients who reported for UGI endoscopy for different UGI symptoms. The data were collected from the computer-based database of the department. The recorded data included information regarding age, gender, the primary symptoms for which the UGI endoscopy was requested, and the endoscopic findings.

All UGI endoscopies were performed by one consultant gastroenterologist. The standard procedure followed at the department was that the patients were informed in detail about the procedure and the risks involved therein. Willing patients were then premedicated with injection midazolam $2 \mathrm{mg}$ and throat spray $4 \%$ lignocaine. During the study period, Pentax Eg 2990 I (Pentax Life Care Division, Hoya Corp., Tokyo, Japan) video endoscope was used to visualize the UGI tract. The endoscopewas disinfected with $2 \%$ glutaraldehyde before the procedure. Esophageal, gastric, and duodenal mucosa were carefully inspectedfor the signs of any noteworthy irregularity. Endoscopic biopsy was carried outwhere indicated.

The presence of any of the following lesions was considered as a notable finding in the UGI, endoscopy: peptic ulcer (gastric or duodenal ulcer, or both), esophagitis, growths in esophagus, stomach, gastroesophageal junction or duodenum, erosive gastritis or duodenitis, hiatalhernia, Barrett's esophagus, esophageal or duodenal stricture, Mallory Weiss tear, foreign body in the esophagus, stomach or duodenum, hookworm infestation, UGI varices (esophageal varices, isolated gastric varices, duodenal varies, others, etc.) achalasia cardia, portal hypertensive gastropathy, and other non-specific gastropathy or duodenopathy.

Patients were stratified into two groups according to theirage: $\leq 50$ years (group 1) and $>50$ years (group 2). Data analysis was performed using Statistical Package for Social Sciences 20 (SPSS Inc., Chicago, IL, USA) for windows. The data were described as mean \pm SD and numbers with percentages. For statistical analysis Pearson's Chi square test was used. All the inferences were made at $95 \%$ confidence interval and $p$-values of $\leq 0.05$ were considered significant.

\section{RESULTS}

A total of 638 patients underwent UGI endoscopy between July 2017 and March 2019. The mean age of the sample was $50.2 \pm 17.4$ years with a range of 7-100 years.There were $431(67.6 \%)$ males (mean age $51.1 \pm$ 17 years, range: $12-100$ years) and 207 (32.4\%) females (mean age: $48.3 \pm 18.1$ years, range: $7-86$ years). There were $318(49.8 \%)$ individuals of age $\leq 50$ years and 320 $(50.2 \%)$ individuals in the age group of $>50$ years. The different complaints for which the patients were referred or the indications have been mentioned in table-I.

The commonest presenting complaint among the recruited patients were decompensated chronic liver disease (CLD) 162 (25.4\%) followed by peptic ulcer disease $147(23 \%)$. The UGI endoscopy was normal in $306(48 \%)$ and abnormal in $332(52 \%)$ patients. The commonest abnormality seen on UGI endoscopy was esophageal varices seen in $167(26.2 \%)$ patients. This was followed by non-specific gastropathy and hiatal hernia seen in $28(4.4 \%)$ and $21(3.3 \%)$ patients respectively (table-I).

On comparison of male and female patients, more males had a positive UGI endoscopy and more females had a normal UGI endoscopy. However, this variation did not show statistical significance $(p=0.333)$. The commonest UGI endoscopic abnormalities were similar in both genders i.e. esophageal varices, non-specific gastropathy, and hiatal hernia (table-II).

While considering comparison of different age groups, significantly large number of individuals of age $\leq 50$ years had a normal UGI endoscopy and significantly large number of patients of age $>50$ years had an abnormal UGI endoscopy $(p<0.001)$. The commonest UGI endoscopic abnormalities were similar in both 
age-groups i.e. esophageal varices, non-specific gastropathy, and hiatal hernia (table-III). and various disorders like UGI bleeding, Mallory Weiss tear; gastric erosions, and foreign bodies can

Table-I: Frequencies and percentages of different presenting complaints and findings on upper gastrointestinal endoscopy.

\begin{tabular}{|c|c|c|c|c|c|}
\hline Presenting Complaints & $\mathbf{n}$ & $\%$ & Upper Gastrointestinal Endoscopy Findings & $\mathbf{n}$ & $\%$ \\
\hline Chronic liver disease & 35 & $(5.5)$ & Normal & 306 & $(48)$ \\
\hline Decompensated chronic liver disease & 163 & $(25.6)$ & Achalasia Cardia & 5 & $(0.8)$ \\
\hline Chronic kidney disease & 5 & $(0.8)$ & Growth esophagus & 7 & $(1.1)$ \\
\hline Carcinoma esophagus & 1 & $(0.2)$ & Growth gastroesophageal junction & 3 & $(0.5)$ \\
\hline Dysphagia & 30 & $(4.7)$ & Growth stomach & 6 & $(0.9)$ \\
\hline Hoarseness of voice & 1 & $(0.2)$ & Growth duodenum & 10 & $(1.6)$ \\
\hline Chronic diarrhea & 8 & (1.3) & Esophageal varices & 167 & $(26.2)$ \\
\hline Hepatitis B Virus infection & 5 & $(0.8)$ & Isolated Gastric varices & 8 & $(1.3)$ \\
\hline Hepatitis $C$ virus infection & 8 & (1.3) & Gastroesophageal varices & 1 & $(0.2)$ \\
\hline Weight loss & 6 & $(0.9)$ & Gastric outlet obstruction & 1 & $(0.2)$ \\
\hline Ascites & 3 & $(0.5)$ & Barret esophagus & 2 & $(0.3)$ \\
\hline Gastroesophageal reflux disease & 9 & (1.4) & Portal hypertensive gastropathy & 12 & (1.9) \\
\hline Gastric outlet obstruction & 2 & $(0.3)$ & Portal hypertensive duodenopathy & 8 & (1.3) \\
\hline Peptic ulcer disease & 147 & (23) & Gastric ulcer & 11 & $(1.7)$ \\
\hline Anemia & 58 & (9.1) & Duodenal ulcer & 12 & (1.9) \\
\hline Persistent vomiting & 22 & (3.4) & Mallory Weiss tear & 4 & $(0.6)$ \\
\hline Generalized Pain abdomen & 3 & $(0.5)$ & Esophagitis & 13 & $(2)$ \\
\hline Hematemesis & 26 & $(4.1)$ & Foreign body esophagus & 1 & $(0.2)$ \\
\hline Persistent vegetative state & 8 & (1.3) & Hiatal hernia & 21 & (3.3) \\
\hline Obstructive jaundice & 2 & $(0.3)$ & Hookworm infestation & 1 & $(0.2)$ \\
\hline Melena & 21 & (3.3) & Stricture esophagus & 9 & (1.4) \\
\hline Upper gastrointestinal bleeding & 22 & (3.4) & Stricture duodenum & 2 & $(0.3)$ \\
\hline Liver tumor & 2 & $(0.3)$ & Non-specific gastropathy & 28 & $(4.4)$ \\
\hline Dyspepsia & 50 & $(7.8)$ & & & \\
\hline Missing values & 1 & & & & \\
\hline
\end{tabular}

Table-II: Comparison of male and female genders for different findings on upper gastrointestinal endoscopy $\left(p=0.333^{*}\right)$.

\begin{tabular}{l|c|c|c|c|c}
\hline $\begin{array}{l}\text { Findings on Upper } \\
\text { Gastrointestinal Endoscopy }\end{array}$ & Male & Female & $\begin{array}{c}\text { Findings on Upper } \\
\text { Gastrointestinal Endoscopy }\end{array}$ & Male & Female \\
\hline Barret esophagus & $1(50 \%)$ & $1(50 \%)$ & Duodenal stricture & $1(50 \%)$ & $1(50 \%)$ \\
\hline Hookworm infestation & $1(100 \%)$ & - & Isolated Gastric varices & $5(62.5 \%)$ & $3(37.5 \%)$ \\
\hline Non-specific gastropathy & $19(67.9 \%)$ & $9(32.1 \%)$ & Portal hypertensive gastropathy & $9(75 \%)$ & $3(25 \%)$ \\
\hline Esophageal stricture & $3(33.3 \%)$ & $6(66.7 \%)$ & Gastric ulcer & $9(81.8 \%)$ & $2(18.2 \%)$ \\
\hline Growth duodenum & $6(60 \%)$ & $4(40 \%)$ & Growth esophagus & $4(51.7 \%)$ & $3(42.9 \%)$ \\
\hline Hiatal hernia & $16(76.2 \%)$ & $5(23.8 \%)$ & Mallory Weiss tear & $3(75 \%)$ & $1(25 \%)$ \\
\hline Achalasia Cardia & $4(80 \%)$ & $2(20 \%)$ & Duodenopathy & $5(62.5 \%)$ & $3(37.5 \%)$ \\
\hline Growth stomach & $4(66.7 \%)$ & $2(33.3 \%)$ & Duodenal ulcer & $10(83.3 \%)$ & $2(16.7 \%)$ \\
\hline $\begin{array}{l}\text { Growth gastroesophageal } \\
\text { junction }\end{array}$ & $3(100 \%)$ & - & Esophagitis & $11(84.6 \%)$ & $2(15.4 \%)$ \\
\hline Esophageal varices & $114(68.3 \%)$ & $53(31.7 \%)$ & Foreign body esophagus & $1(100 \%)$ & - \\
\hline Gastric outlet obstruction & - & $1(100 \%)$ & Gastroesophageal varices & $1(100 \%)$ & - \\
\hline
\end{tabular}

*Pearson's Chi square/ Fisher Exact test

\section{DISCUSSION}

UGI endoscopy is a standout amongst the most precise, speedy, and economical investigative instruments for a broad range of gastrointestinal disorders, particularly under situations when other investigations are unconvincing. Not with standing its diagnostic use, UGI endoscopy also has a time-honored curativerole successfully betreated at endoscopy. Therefore, even withchanging indications over a period, the disorders requiring UGI endoscopy for diagnostic or therapeutic purposes have demonstrated an increasing tendency.

In our study, we observed a male preponderance, which is in line with other studies done by Rajendran et $a l^{1}$, Padma et al ${ }^{10}$ and Hadayat et al11. The reason for 
increased male subjects in the study is generally related to higher prevalence of smoking, tea intake, use of soda drinks, and betel nut chewing among male people. All these factors orchestrate a pivotal role in the development of UGI problems.
$14(26.4 \%)$ followed by Candidal esophagitis 12 (22.6\%) as the common findings. Gado et al ${ }^{9}$, observed the commonest significant pathologies being pepticulcer, esophagitis, and erosive gastroduodenitis, which were diagnosed in $18 \%, 14 \%$, and $8 \%$ of the patients. The

Table-III: Comparison of age groups for different findings on upper gastrointestinal endoscopy $\left(p<0.001^{*}\right)$.

\begin{tabular}{l|c|c|c|c|c}
\hline $\begin{array}{l}\text { Findings on Upper } \\
\text { Gastrointestinal Endoscopy }\end{array}$ & $\begin{array}{c}\text { Age } \leq \mathbf{5 0} \\
\text { years }\end{array}$ & $\begin{array}{c}\text { Age }>\mathbf{5 0} \\
\text { years }\end{array}$ & $\begin{array}{c}\text { Findings on Upper } \\
\text { Gastrointestinal Endoscopy }\end{array}$ & $\begin{array}{c}\text { Age } \leq 50 \\
\text { years }\end{array}$ & $\begin{array}{c}\text { Age }>50 \\
\text { years }\end{array}$ \\
\hline Barret esophagus & - & $2(100 \%)$ & Duodenal stricture & $2(100 \%)$ & - \\
\hline Hookworm infestation & - & $1(100 \%)$ & Isolated Gastric varices & $1(12.5 \%)$ & $7(87.5 \%)$ \\
\hline Non-specific gastropathy & $11(39.3 \%)$ & $17(60.7 \%)$ & Portal hypertensive gastropathy & $7(58.3 \%)$ & $5(41.7 \%)$ \\
\hline Esophageal stricture & $3(33.3 \%)$ & $6(66.7 \%)$ & Gastric ulcer & $4(36.4 \%)$ & $7(63.6 \%)$ \\
\hline Growth duodenum & $3(30 \%)$ & $7(70 \%)$ & Growth esophagus & $2(28.6 \%)$ & $5(71.4 \%)$ \\
\hline Hiatal hernia & $6(28.6 \%)$ & $15(71.4 \%)$ & Mallory Weiss tear & $3(75 \%)$ & $1(25 \%)$ \\
\hline Achalasia Cardia & $4(80 \%)$ & $1(20 \%)$ & Duodenopathy & $5(62.5 \%)$ & $3(37.5 \%)$ \\
\hline Growth stomach & $2(33.3 \%)$ & $4(66.7 \%)$ & Duodenal ulcer & $5(41.7 \%)$ & $7(58.3 \%)$ \\
\hline $\begin{array}{l}\text { Growth gastroesophageal } \\
\text { junction }\end{array}$ & $1(33.3 \%)$ & $2(66.7 \%)$ & Esophagitis & $6(46.2 \%)$ & $7(53.8 \%)$ \\
\hline Esophageal varices & $51(30.5 \%)$ & $116(69.5 \%)$ & Foreign body esophagus & - & $1(100 \%)$ \\
\hline Gastric outlet obstruction & $1(33.3 \%)$ & $2(66.7 \%)$ & Gastroesophageal varices & 1 & $1(100 \%)$ \\
\hline
\end{tabular}

*Pearson's Chi square/ Fisher Exact test

The commonest presenting features among the recruited patients were decompensated CLD 163 (25.6\%) followed by peptic ulcers $147(23 \%)$ and anemia 58 $(9.1 \%)$. Other studies have reported diverse presenting complaints among the patients who reported for UGI endoscopy. The most common symptom encountered by Parashar and colleagues ${ }^{12}$, was epigastric pain seen in $49(92.5 \%)$ patients followed by anorexia and weight loss in $45(84.9 \%)$, and $41(77.4 \%)$ patients respectively in an Indian hospital. Gado et al ${ }^{9}$, observed dyspepsia $1400(31 \%)$, UGI bleeding 1155 (26\%), and banding or sclerotherapy of varices $897(20 \%)$ as the most frequent indications for UGI endoscopy in an Egyptian institute. Khurram et al ${ }^{13}$, noted dyspepsia (42.6\%), UGI bleed $(32.8 \%)$, and evaluation of the CLD (10.2\%) as the common indications for the procedure in a Pakistani teaching hospital. Rajendran and colleagues 1 reported nausea/vomiting accounting for 50\%, followed by weight loss $(20 \%)$, and gastrointestinal bleeding $(20 \%)$ as the most common symptoms for patients reporting to an Indian gastroenterology unit.

The commonest abnormalities seen by us on UGI endoscopy were esophageal varices $(26.2 \%)$. non-specific gastropathy $(4.4 \%)$, and hiatal hernia $(3.3 \%)$. A review of the previous relevant studies also shows a variability in terms of commonly reported findings on UGI endoscopy. Mahmood et al ${ }^{14}$, reported gastritis $106(13.85 \%)$, esophagitis $85(11.1 \%)$, duodenal ulcer 62 $(8.1 \%)$, and hiatal hernia $55(7.2 \%)$ as the common findings. Parashar and colleagues ${ }^{12}$, foundantral gastritis frequent abnormal findings noted by Padma and $\mathrm{Mu}-$ rugan 10 on UGI endoscopy included gastritis in 987 cases $(44.9 \%)$, esophageal varices in 195 cases (8.9\%), lax lower esophageal junction withesophagitis in 178 cases $(8.09 \%)$, and duodenal ulcers in 124 cases (5.6\%). Thomson and colleagues ${ }^{15}$ identified erosive esophagitis $451(43 \%)$, gastric erosions $102(9.8 \%)$, and peptic ulcers $55(5.3 \%)$ as the frequent findings. Inayatullah et $a l^{16}$, acknowledged gastroduodenitis (20\% cases) followed by gastriculcers (5.4\% cases) as the most frequent findings. In a series by Hadayat et al ${ }^{11}$, the most common endoscopic finding were esophageal varices 234 $(92.9 \%)$ and portal hypertensive gastropathy $98(38.9 \%)$. Malghani and colleagues ${ }^{17}$, in recent Pakistani study, discovered esophageal varices in 371 (50.8\%) patients, followed by gastropathy $114(15.6 \%)$, gastritis 68 (9.3\%), and cardio-fundal varices $58(7.9 \%)$ in a descending order of frequency.

In our study, normal endoscopy was reported more commonly in females $(31.2 \%)$ ascompared to males $(28.6 \%)$ showing that more females suffered from functional dyspepsia in our setup. Similar findings were observed by Jamaludin and Chong ${ }^{18}$ and Mehmood et al4. We did not find any difference among the two genders for the incidence of common UGI endoscopy findings. In the same line, Hadayat et al11, found equal distribution among males and females inthe UGI endoscopy findings. However, some studies have found an association between a finding and gender. Padma and Murugan ${ }^{10}$ reported that duode- 
nal ulcers and esophageal carcinomas were more common among males. Malghani and colleagues ${ }^{17}$, found a distinct predilection of different UGI endoscopy findings for the two genders. They found that esophageal varices, gastritis, gastric carcinomas, and duodenal ulcers and were more expectedto be discovered in male patients as compared to female patients $(p=0.039)$ while esophageal and gastric ulcers and portal hypertensive gastropathy were more expectedto be found in female patients.

Comparing the two age groups, a normal study was significantly more observed in younger patients that, in turn, means that younger patients are more likely to present with functional UGI symptoms than older people. Jamaludin and Chong18, studied the effect of age on the presence of significant findings on UGI endoscopy and concluded that patients $>50$ years of age were more likely ( $p$-value $<0.05$ ) to have positive findings on UGI endoscopy than younger patients (age $\leq 50$ years). The findings of Gato et al ${ }^{9}$, also endorse above findings as the significant UGI lesions were more commonin the older people. Esophagitis, erosivegastritis and duodenitis, peptic ulcer, and UGI malignancies, all were associated with the age in terms of statistical significance. Abnormal UGI findings were more commonly observed in patients above 40 years of age as compared to younger patients (76.6\% Vs $63.4 \%)$ by Mehmood et al ${ }^{4}$. Thomson and colleagues ${ }^{15}$, in their study, also disclosed that clinically significant findings on UGI endoscopywere more common in patients of older age group ( $>50$ years of age) than in patients of younger age. Malghani and colleagues ${ }^{14}$, reported that esophageal varices and gastric varices were more likely to be found in patients from the middle age group $(p<0.001)$, whereas gastritis, gastric erosions, duodenitis, and duodenal ulcer were more likely to be found in older ( $>60$ years) patients $(p<0.001)$. These observations defend the opinion that endoscopy should right away be done for patients above 45 with dyspepsia.

\section{CONCLUSION}

Our study showed that the commonest finding on UGI endoscopy were esophageal varices and non-specific gastropathies. Female patients and patients $\leq 50$ years had a higher prevalence of a normal UGI endoscopy without a specific finding. The commonly observed UGI endoscopy findings, were generally similar among the genders and the age-groups.

\section{CONFLICT OF INTEREST}

This study has no conflict of interest to be declared by any author.

\section{REFERENCES}

1. Rajendran K, Chidambaranathan S, Sathyanesan J, Palaniappan R. Spectrum of upper gastrointestinal endoscopy findings in patients with dyspepsia and its relation to alarm symptoms. Int J Med Health Res 2018; 4(10): 175-77.

2. Ahmad M, Ahmad M, Munir T. Prevention of functional dyspepsia with carica papaya extract. Ann King Edward Med Uni 2018 24(1): 60-68.

3. Addula M, Wilson VED, Reddymasu S, Agrawal DK. Immunopathological and molecular basis of functional dyspepsia and current therapeutic approaches. Expert Rev Clin Immunol 2018; 14(10): 831-40.

4. Mehmood K, Saeedi MI, Muhammad R, ud Din Z. Upper gastrointestinal endoscopic findings in patients with dyspepsia. J Postgrad Med Inst 2011; 20(1): 70-73.

5. Subramaniam S. Competency in polypectomy: when desirable becomes essential. Gastrointest Endosc 2018; 87(3): 645-47.

6. Teriaky A, Al-Nasser A, McLean C, Gregor J, Yan B. The Utility of Endoscopic Biopsies in Patients with Normal Upper Endoscopy. Can J Gastroenterol Hepatol 2016; 2016(1): 3026563-65.

7. de Jong JJ, Lantinga MA, Drenth JP. Prevention of overuse: A view on upper gastrointestinal endoscopy. World J Gastroenterol 2019; 25(2): 178-89.

8. EpiTools Epidemiological Calculators. Aus Vet. Accessed 29 December 2018. [Internet] Available from: http://epitools. ausvet.com.au/content. php?page=1Proportion.

9. Gado A, Ebeid B, Abdelmohsen A, Axon A. Endoscopic evaluation of patients with dyspepsia in a secondary referral hospital in Egypt. Alexandria J Med 2015; 51(3): 179-84.

10. Padma S, Murugan R. Disease pattern by upper gastrointestinal endoscopy in rural areas of Tiruchirappalli district carried out at $\mathrm{CMCH}$ and $\mathrm{RC}$ Irungalur, retrospective study and comparative analysis with other contemporary studies in India. Int Surg J 2018; 5(3): 965-70.

11. Hadayat R, Jehangiri AU, Gul R, Khan AN, Said K, Gandapur A. Endoscopic findings of upper gastrointestinal bleeding in patients with liver cirrhosis. J Ayub Med Coll Abbottabad 2015; 27(2): 391-94.

12. Parashar R, Kaushik D, Malik PK. The study of clinical and endoscopic spectrum of upper gastrointestinal manifestations in HIV patients. Int J Res Med Sci 2018; 6(5): 1588-93.

13. Khurram M, Khaar HT, Hasan Z, Umar M, Javed S, Asghar T, et al. A 12 years audit of upper gastrointestinal endoscopic procedures. J Coll Physicians Surg Pak 2003; 13(6): 321-24.

14. Mahmood K, Saeedi MI, Muhammad R. Upper gastrointestinal endoscopic findings in patients with dyspepsia. J Postgrad Med Inst 2011; 20(1): 70-73.

15. Thomson AB, Barkun AN, Armstrong D, Chiba N, White RJ, Daniels $\mathrm{S}$, et al. The prevalence of clinically significant endoscopic findings in primary care patients with uninvestigated dyspepsia: the Canadian Adult Dyspepsia Empiric Treatment - Prompt Endoscopy (CADET-PE) study. Aliment Pharmacol Ther 2003; 17(12): 1481-91.

16. Inayatullah M, Nazish Z, Akhtar MS, Anjum AH, Naqvi AB. Dyspepsia and upper gastrointestinal endoscopy; Multan experience. Prof Med J 2008; 15(1): 143-47.

17. Malghani WS, Malik R, Chaudhary FM, Tameez Ud Din A, Shahid M, Ahmad S, et al. Spectrum of endoscopic findings in patients of upper gastrointestinal bleeding at a tertiary care hospital. Cureus 2019; 11(4): e4562-65.

18. Jamaludin AZF, Chong VH. Spectrum of endoscopic findings in patients referred for suspected upper gastrointestinal bleeding. Brunei Darussalam J Health 2007; 2(1): 39-43. 